\title{
Promyelocytic sarcoma of the sternum: a case report and review of the literature
}

\author{
Xavier Thomas, Youcef Chelghoum \\ Department of Hematology, Hôpital Edouard Herriot, Hospices Civils de Lyon, Lyon, France
}

p-ISSN 1738-7949 / e-ISSN 2092-9129

DOI: $10.5045 / \mathrm{kjh} .2011 .46 .1 .52$

Korean J Hematol 2011;46:52-6.

Received on September 6, 2010

Revised on January 31, 2011

Accepted on January 31, 2011

\section{Correspondence to}

Xavier Thomas, M.D., Ph.D.

Department of Hematology, Hôpital

Edouard Herriot, 5 place d'Arsonval, 69437

Lyon, France

Tel: +33-4-72117395

Fax: +33-1-72117404

E-mail: xavier.thomas@chu-lyon.fr

(C) 2011 Korean Society of Hematology
This study reports a case of promyelocytic sarcoma that developed as a solitary sternal mass without any clinical evidence of acute promyelocytic leukemia. The case presented the diagnostic difficulties common to all aleukemic granulocytic sarcomas, and diagnosis was made possible by local identification of the $P M L / R A R \alpha$ fusion gene by fluorescent in situ hybridization. The patient was treated by surgery followed by chemotherapy plus all-trans retinoic acid therapy and local radiotherapy.

Key Words Promyelocytic sarcoma, $P M L / R A R \alpha$ fusion, Acute promyelocytic leukemia

\section{INTRODUCTION}

Myeloid sarcoma (MS) (initially known as granulocytic sarcoma, and then chloroma) is a rare localized tumor composed of immature granulocytic precursor cells. This extramedullary tumor can affect any organ and can present before, in concurrence with, or after the diagnosis of acute myeloid leukemia (AML) or other myeloproliferative disorders, or as a manifestation of disease relapse [1]. The World Health Organization (WHO) classification recognizes different variants of this tumor based on the predominant cell type and the degree of cell maturation [2]. Extramedullary disease is associated with every cytological subset of FrenchAmerican-British (FAB) individuals; the disease is frequently found in patients with a monocytic component (FAB M4 and M5), but it is seldom found in patients with acute promyelocytic leukemia (APL) [3].

APL accounts for approximately 10\% of AML cases, and is characterized by a favorable clinical outcome [4]. Several types of extramedullary leukemic infiltrates have been reported in APL patients; the skin (leukemia cutis) and the central nervous system (CNS) are the preferred sites of extramedullary involvement in APL. Among primary extramedullary localizations, chloroma is an uncommon patho- gnomonic lesion, and it is more appropriately termed as promyelocytic sarcoma (PS) when it occurs in this subset of leukemia.

In this report, we present a case of PS that presented as a solitary sternal mass without any clinical evidence of hemopathy. A conclusive diagnosis of PS was made only after local identification of the $P M L / R A R \alpha$ fusion gene by using fluorescent in situ hybridization (FISH).

\section{CASE REPORT}

A 19-year-old man who had a history of asthma and resultant steroid treatment presented with sternal pain, fever, and fatigue in December 2009. Physical examination revealed a solid sternal extramedullary mass with local erythema, and the patient reported persistent pain. Neither trauma nor infection was reported. Magnetic resonance imaging (MRI) scans showed edema, periosteal reaction, and irregular signals from the bone marrow (Fig. 1). Antibiotic therapy was initiated because of the putative diagnosis of osteomyelitis. However, the pain persisted, thereby prompting reevaluation. The blood cell count was normal: hemoglobin, $15.9 \mathrm{~g} / \mathrm{dL}$; red blood cells, $5.5 \times 10^{12} / \mathrm{L}$; white blood cells, $7.4 \times 10^{9} / \mathrm{L}$ (with neutrophils, $3.2 \times 10^{9} / \mathrm{L}$; eosinophils, $0.4 \times 10^{9} / \mathrm{L}$; lymphocytes,

This is an Open Access article distributed under the terms of the Creative Commons Attribution Non-Commercial License (http://creativecommons.org/licenses/by-nc/3.0) which permits unrestricted non-commercial use, distribution, and reproduction in any medium, provided the original work is properly cited. 

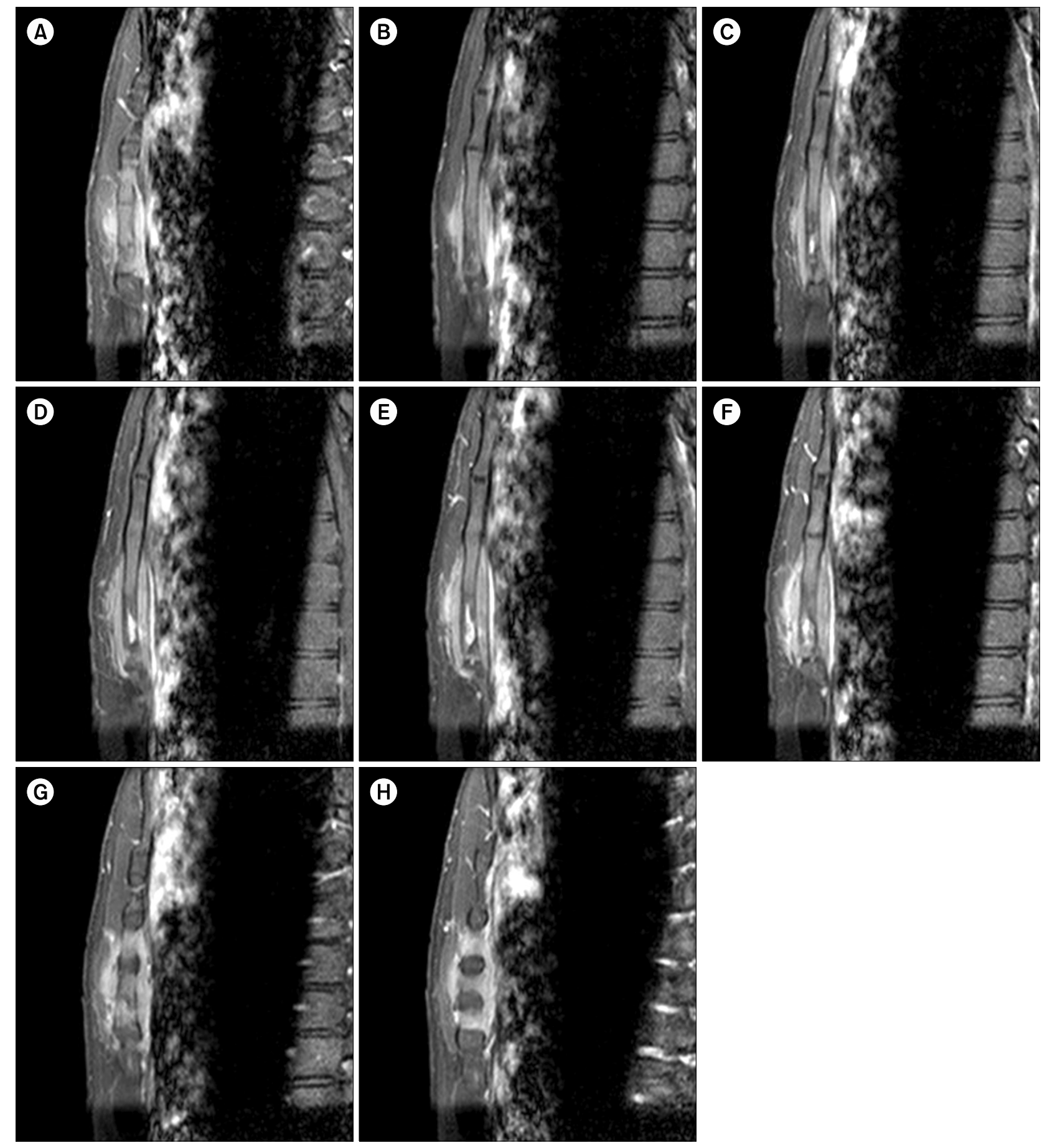

Fig. 1. Magnetic resonance imaging of the sternum. Sagittal-weighted images $(\mathrm{A}$ to $\mathrm{H})$ show injury to almost the entire sternum. The sternum shows an obvious abnormality at the distal end with a centro-osseous necrotic mass measuring $24 \mathrm{~mm}$ in transverse section, $7 \mathrm{~mm}$ in thickness, and 20 $\mathrm{mm}$ in height. The soft tissue swelling in the pre- and retro-sternal areas is significant with intense enhancement spanning nearly $50 \mathrm{~mm}$.

$2.9 \times 10^{9} / \mathrm{L}$; and monocytes, $\left.0.4 \times 10^{9} / \mathrm{L}\right)$; and platelets, $202 \times$ $10^{9} / \mathrm{L}$. In March 2010, the patient underwent surgery. A lobulated tumor that was stuck to the sternum but did not infiltrate it was removed during surgery. Complementary biopsies of the sternum and the peri-sternal tissue were performed. Histopathological examination of the tissue revealed an infiltration by myeloid cells, of which some cells had a promyelocytic morphology and contained azurophilic granulations and Auer rods. The immunophenotypic study was limited to specific antigens, but most of the cells did not express CD34. Cytogenetic studies of the PML/RARa fusion gene by using FISH (LSI probe) and PML/RAR $\alpha$ dual color probe (Dual fusion translocation probe, Vysis/Abbot) showed $\mathrm{t}(15 ; 17)$ (q22;q21-22) (Fig. 2). Diagnostic workup 


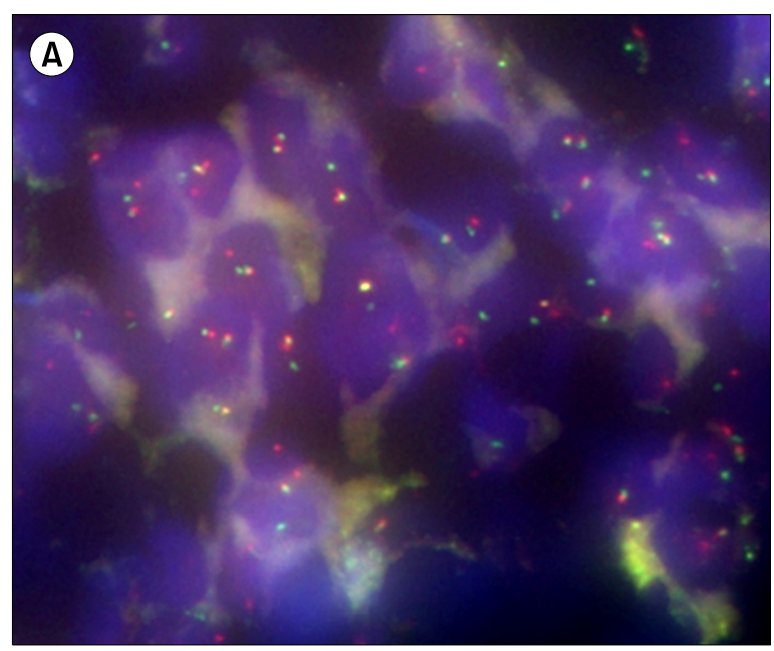

B

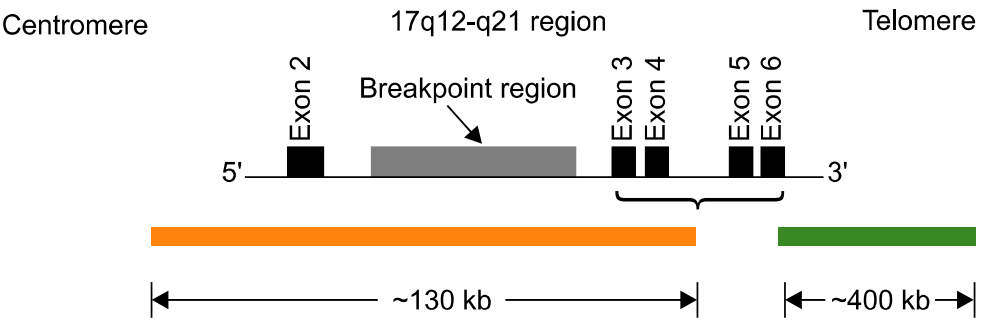

LSI 5' PML dual color, break apart

LSI 3' RAR $\alpha$

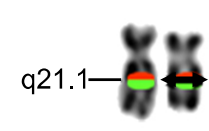

Ch 17

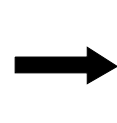

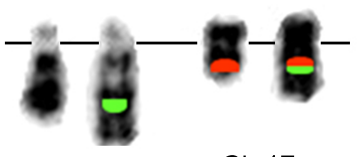

Ch 15
Ch 17

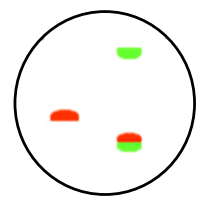

(1)
Fig. 2. The reciprocal and balanced $t(15 ; 21)$, involving the $P M L$ gene on chromosome $15 q 22$ and the $R A R \alpha$ gene on chromosome $17 q 12.1$, is a characteristic molecular feature of APL. In APL cells containing $\mathrm{t}(15 ; 17), 1$ orange $(P M L), 1$ green $(R A R \alpha)$, and 1 fusion $(P M L / R A R \alpha)$ signal pattern is observed (A). Two gene fusion products result from this translocation and encode the functional chimeric proteins: $P M L / R A R \alpha$ and $R A R \alpha / P M L$. The LSI $P M L / R A R \alpha$ probe is a mixture of $2 \mathrm{FISH} D N A$ probes. $L S$ $P M L$ is labeled in spectrum orange and LSI RAR $\alpha$ is labeled in spectrum green (B). of the patients, including determination of the coagulation profile and assessment of the bone marrow aspirate, yielded normal results, and neither atypical promyelocytes nor blast cells was detected in the peripheral blood and bone marrow. In addition, negative results were obtained in cytogenetic and PCR analysis for $P M L / R A R \alpha$ transcription in peripheral blood and bone marrow cells. Taken together, the results suggested a diagnosis of PS. The patient was treated in accordance with the French APL-2006 trial: a combination of all-trans retinoic acid (ATRA) $\left(45 \mathrm{mg} / \mathrm{m}^{2} /\right.$ day for 30 days), idarubicin $\left(12 \mathrm{mg} / \mathrm{m}^{2} /\right.$ day for 3 days), and cytarabine (200 $\mathrm{mg} / \mathrm{m}^{2} /$ day for 7 days) was administered. Further evaluation of the patient after induction therapy was not possible because of the specific morphological and molecular results at the time of diagnosis. However, the patient still received 2 additional courses of consolidation chemotherapy followed by local radiotherapy in the sternal region, and a 2-year maintenance therapy involving oral administration of 6-mercaptopurine and methotrexate was scheduled.

\section{DISCUSSION}

The problems related to the diagnosis and prognosis of MS can be attributed to its clinical mode of appearance. Since most patients never develop systemic disease, a correct and timely diagnosis may be rather difficult. Diagnosis is easier when MS is concomitant with leukemia [5-7], or when MS develops in patients previously treated for leukemia [8]. Diagnosis is more problematic when MS precedes acute leukemia. Cases of MS are often misdiagnosed as other neoplasms, mainly as malignant lymphomas. In the cases of APL, extramedullary disease is generally observed at the time of relapse and presents as a solitary localization or in association with the hematological features of the disease. The occurrence of extramedullary disease in patients with APL has been increasing since the introduction of all-trans retinoic acid (ATRA) therapy [8]. Such findings have raised several questions regarding the use of this therapy; the increase in the occurrence of extramedullary diseases has been linked to a direct effect of ATRA on adhesion molecules, 
Table 1. Published cases of isolated myeloid sarcoma in APL at diagnosis.

\begin{tabular}{|c|c|c|c|}
\hline Reference & Site of involvement & Diagnosis of APL & Initial treatment \\
\hline Kubonishi et al. (1984) [11] & Mediastinal tumor & APL diagnosed 8 mo later & Surgery+radiotherapy \\
\hline Ajarim et al. (1990) [6] & Thymus & Concomitant hematological features & Chemotherapy \\
\hline Brown et al. (1992) [7] & Optic nerve & Concomitant hematological features & ATRA alone \\
\hline Tosi et al. (1995) [12] & L4-epidural & Concomitant hematological features & $\begin{array}{l}\text { Surgery }+ \text { ATRA + chemotherapy }+ \\
\text { radiotherapy }\end{array}$ \\
\hline Savranlar et al. (2004) [10] & Thoracic-epidural & APL diagnosed 10 mo later & Surgery+radiotherapy \\
\hline Gopal et al. (2005) [14] & Testicle & Cytogenetic features at relapse & Surgery \\
\hline Fukushima et al. (2006) [5] & Cerebellum & Concomitant hematological features & Surgery+chemotherapy \\
\hline Worch et al. (2008) [13] & $\begin{array}{l}\text { Lytic lesions of humerus, } \\
\text { tibia, femur }\end{array}$ & Molecular hematological features & ATRA+chemotherapy \\
\hline Present case (2010) & Sternum & Molecular features on tumor cells & $\begin{array}{l}\text { Surgery }+ \text { ATRA }+ \text { chemotherapy }+ \\
\text { radiotherapy }\end{array}$ \\
\hline
\end{tabular}

Abbreviations: APL, acute promyelocytic leukemia; ATRA, all-trans retinoic acid therapy; mo, months.

which increases the infiltration capability of blastic cells [9]. The increase in the occurrence of extramedullary disease can also be a consequence of the prolonged survival of patients who receive ATRA [8]. Furthermore, the occurrence of the ATRA syndrome has been recognized to be a significant risk factor for extramedullary involvement at relapse [9].

The presence of an isolated localization is much more uncommon in APL at the time of initial diagnosis. In rare cases, MS originates in the subperiosteal regions of the bones (ribs, sternum, or orbital bones) several months before the clinical detection of leukemia, and subsequently spreads to soft tissues. MS can also originate in other regions, such as the spinal epidural space, thereby showing signs and symptoms of spinal compression. PS may have totally gone undetected on initial diagnosis [10-12], and it may actually be diagnosed later with bone marrow infiltration by promyelocytic malignant cells at the time of relapse. PS may be correctly diagnosed initially by identifying the specific translocation and/or molecular rearrangement in the tumor cells and also by assessing the molecular hematological features, even though the bone marrow aspirate does not show any blastic infiltration [13, 14] (Table 1).

A diagnosis of MS is considered as a possible sign of APL. In this report, we report a rare case of MS; diagnosis of the disease was made after surgical intervention and cytogenetic analysis of the tumor cells. Correct and timely diagnosis is a prerequisite for optimal treatment and outcome. Therefore, establishing an accurate histological diagnosis is a fundamental requirement. The optimal management of patients with this form of APL has not been critically assessed. In some MS cases, the patients do not show any clear leukemic transformation in the later stages. However, the consensus is that all patients showing MS should be treated with intensive chemotherapy [15]. When left untreated, most cases progress to overt leukemia; a majority of the cases show AML transformation in about 10 months [10-12, 14]. Similarly, therapy restricted to local procedures increases the risk of systemic disease. Radiation and intensive systemic therapy may therefore certainly be considered [15], and treatment might involve the same chemotherapeutic schedules that are generally used in leukemia with a "classic" presentation. The standard treatment for APL consists of ATRA combined with conventional chemotherapy [4]. Our patient could not be included into the French APL-2006 clinical trial, but he was treated similarly with an induction course combining ATRA with chemotherapy followed by 2 courses of consolidation chemotherapy and a 2-year maintenance therapy. Furthermore, complementary sternal irradiation was scheduled between the consolidation and maintenance phases.

\section{REFERENCES}

1. Neiman RS, Barcos M, Berard C, et al. Granulocytic sarcoma: a clinicopathologic study of 61 biopsied cases. Cancer 1981;48:1426-37.

2. Jaffe ES, Harris NL, Stein H, Vardimann JW, eds. World Health Organization Classification of Tumours of Haematopoietic and Lymphoid Tissues. Lyon, France: IARC Press, 2001.

3. Liso V, Specchia G, Pogliani EM, et al. Extramedullary involvement in patients with acute promyelocytic leukemia: a report of seven cases. Cancer 1998;83:1522-8.

4. Sanz MA, Grimwade D, Tallman MS, et al. Management of acute promyelocytic leukemia: recommendations from an expert panel on behalf of the European LeukemiaNet. Blood 2009;113:1875-91.

5. Fukushima S, Terasaki M, Tajima Y, Shigemori M. Granulocytic sarcoma: an unusual complication of acute promyelocytic leukemia causing cerebellar hemorrhage. Case report. J Neurosurg 2006;105:912-5.

6. Ajarim DS, Santhosh-Kumar CR, Higgy KE, el Saghir NS, Almomen AK, Shipkey FD. Granulocytic sarcoma of the thymus in acute promyelocytic leukaemia. Clin Lab Haematol 1990;12:97-9.

7. Brown DM, Kimura AE, Ossoinig KC, Weiner GJ. Acute promyelocytic infiltration of the optic nerve treated by oral trans-retinoic acid. Ophthalmology 1992;99:1463-7.

8. Specchia G, Lo Coco F, Vignetti M, et al. Extramedullary involvement at relapse in acute promyelocytic leukemia patients treated or not with all-trans retinoic acid: a report by the Gruppo Italiano Malattie Ematologiche dell'Adulto. J Clin Oncol 2001;19:4023-8. 
9. Ko BS, Tang JL, Chen YC, et al. Extramedullary relapse after all-trans retinoic acid treatment in acute promyelocytic leukemia the occurrence of retinoic acid syndrome is a risk factor. Leukemia 1999;13:1406-8.

10. Savranlar A, Ustündag Y, Ozer T, et al. A thoracic-epidural granulocytic sarcoma case that was diagnosed preceding the onset of and that recurred co-incidental to acute promyelocytic leukemia, which developed after surgical treatment. Acta Med Okayama 2004;58:251-4.

11. Kubonishi I, Ohtsuki Y, Machida K, et al. Granulocytic sarcoma presenting as a mediastinal tumor. Report of a case and cytological and cytochemical studies of tumor cells in vivo and in vitro. Am J Clin Pathol 1984;82:730-4.
12. Tosi A, De Paoli A, Fava S, et al. Undifferentiated granulocytic sarcoma: a case with epidural onset preceding acute promyelocytic leukemia. Haematologica 1995;80: 44-6.

13. Worch J, Ritter J, Frühwald MC. Presentation of acute promyelocytic leukemia as granulocytic sarcoma. Pediatr Blood Cancer 2008;50:657-60.

14. Gopal S, Marcussen S, Dobin SM, Koss W, Donner LR. Primary myeloid sarcoma of the testicle with $\mathrm{t}(15 ; 17)$. Cancer Genet Cytogenet 2005; 157:148-50.

15. Tsimberidou AM, Kantarjian HM, Estey E, et al. Outcome in patients with nonleukemic granulocytic sarcoma treated with chemotherapy with or without radiotherapy. Leukemia 2003;17: 1100-3.

\section{Filler Photo}

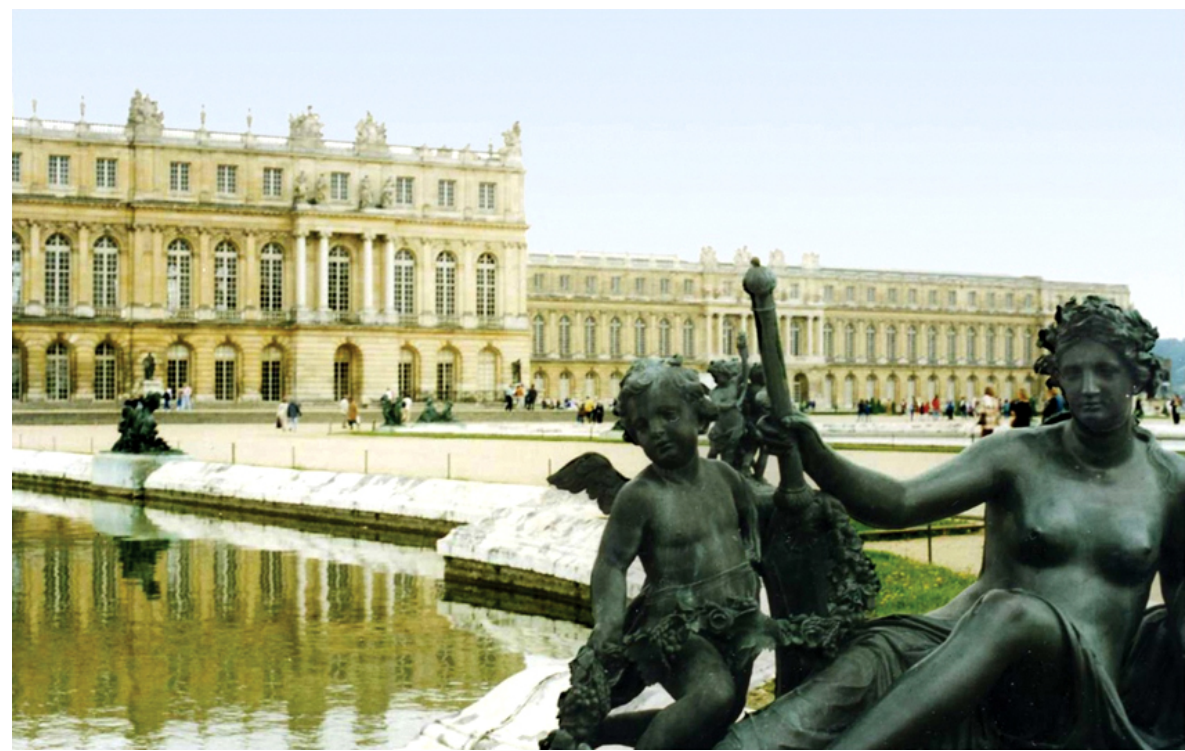

Château de Versailles, France

S.W. Kwon 